\section{Medical funding group calls for clamp-down on hype}

David Adam, London

Researchers who talk to the press prematurely about unpublished research could soon face harsher sanctions than the odd disapproving glance from a colleague. Under research misconduct guidelines just released by an association of British medical charities, they could be blacklisted for funding, the head of the association says.

Diana Garnham, chief executive of the London-based Association of Medical Research Charities (AMRC), which issued the guidelines on 17 October, says its members are fed up dealing with the fallout from over-hyped or misleading results. "Scientists don't do their work in a vacuum," she says. "There is an audience for whom their work is directly relevant, and they need to bear that in mind."

The guidelines state simply that researchers should be "especially careful" when discussing incomplete work, and are intended to coax universities and other research institutions into drawing up their own rules. They also point out that the aim of disseminating research "should not be primarily to seek publicity for the researcher, the research institution or the funder". From January next year, the AMRC says it will recommend that its members fund only researchers at institutions that have published specific standards for sound scientific conduct.

The AMRC counts major research funders such as the Wellcome Trust and Cancer Research UK among its members — but it remains unclear how much impact the new proposals will have. The Wellcome Trust has already issued guidelines of its own, which came into force earlier this month (see Nature 412, 667; 2001).

Robert Terry, a senior policy adviser at the trust, says that the charity is unlikely to act immediately on the new recommendations.

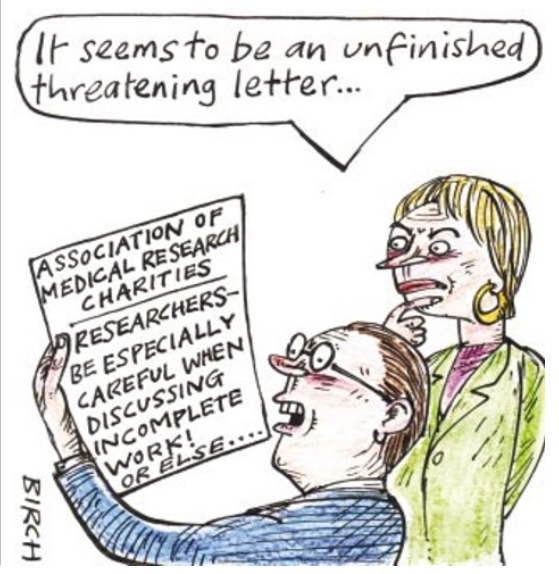

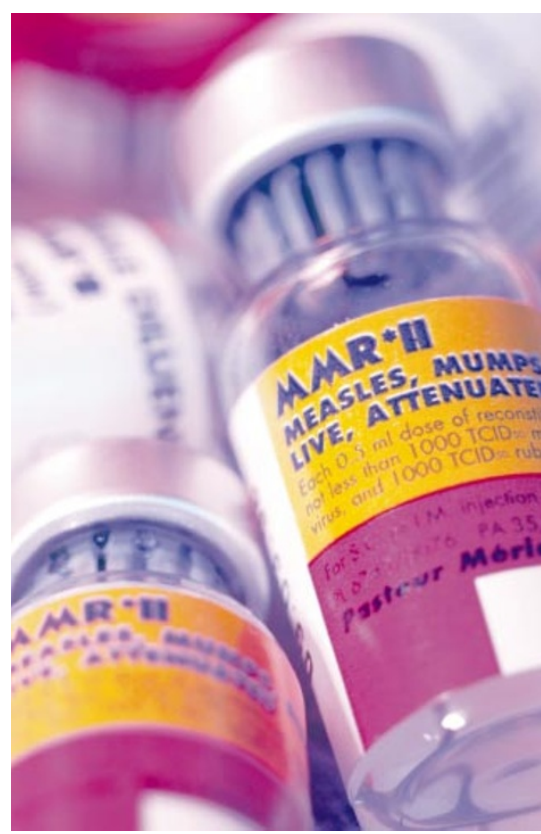

Research on the health risks of the MMR vaccine reached the press before it was finalized.

“They are a useful addition but I don't think we would go that far," he says. The existing peer-review process of grant applications can already take into account bad publication practices or the over-promotion of results, Terry claims.

But the AMRC says that more action is needed to deal with what it says are a small but nonetheless significant number of incomplete research findings — such as those concerning a possible link between childhood autism and the combined measles, mumps and rubella (MMR) vaccine - that are promoted by researchers and then heavily reported in the press.

"When scientists want to protect the commercial outcome of their research they stay in control of the timing of its release, so why should this be any different?" says Garnham. "We don't go as far as saying that their funding should be cut off — but I think some of our charities would be willing to do that."

Others observers say that it will be hard to hold researchers accountable for premature release of their results, still less for their misinterpretation by the media. "Some sort of quality-control mechanism is needed," says Bob Ward, a spokesman for the Royal Society, which will shortly announce its own inquiry into the dissemination of research results, "but it's not a straightforward issue."

www.amrc.org.uk

\section{National academies slam Bush proposal for data security}

\section{Erika Check, Washington}

America's scientific élite has issued a stern warning about what it says are the pitfalls of the Bush administration's proposal to create a new category of sensitive, but unclassified, technical information.

The presidents of the National Academy of Sciences, National Academy of Engineering and the Institute of Medicine released a joint statement on 18 October rejecting the proposed category, which the White House says is needed to prevent the misuse of certain scientific and technical information. The administration hasn't released details of what kinds of information would be included in the category, which it calls 'sensitive homeland-security information' (see Nature 418, 906; 2002).

"Experience shows that vague criteria of this kind generate deep uncertainties among both scientists and officials responsible for enforcing regulations," the academies' statement says. "The inevitable effect is to stifle scientific creativity and to weaken national security."

At a hearing of the House Committee on Science on 10 October, John Marburger, director of the White House Office of Science and Technology Policy (OSTP), sought to assuage scientists' concerns about the proposal. He said that the category guidelines, when released, would not cover results from basic research. The designation is for the type of information held by the government that is not routinely released to the public, such as lawenforcement data, he told the hearing.

But Bill Colglazier, executive officer of the National Academy of Sciences, says that without written guidelines, scientists can't accept Marburger's assurances. "The concern is that if you leave this category very vague and amorphous, it could end up causing problems in the research community," says Colglazier.

Biologist M. R. C. Greenwood, the chancellor of the University of California, Santa Cruz, agrees that it would be a bad idea to set up a category of unclassified but restricted information. "We would be better off building up science and technical enterprise so we have talent and ideas to outwit any threat that comes this way, as opposed to trying to keep information from escaping," says Greenwood, who served as an associate director of the OSTP in the Clinton administration. www.nas.edu 